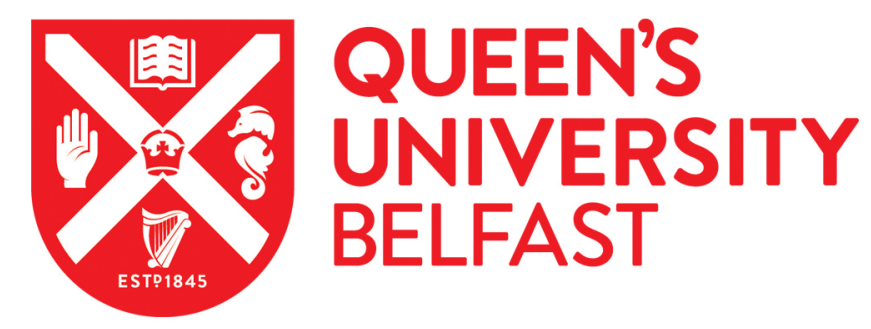

\title{
The reliability and validity of a child and adolescent participation in decision making questionnaire
}

O'Hare, L., Santin, O., Winter, K., \& McGuinness, C. (2016). The reliability and validity of a child and adolescent participation in decision making questionnaire. Child: Care, Health and Development, 42(5), 692-698. https://doi.org/10.1111/cch.12369

\section{Published in:}

Child: Care, Health and Development

\section{Document Version:}

Peer reviewed version

\section{Queen's University Belfast - Research Portal:}

Link to publication record in Queen's University Belfast Research Portal

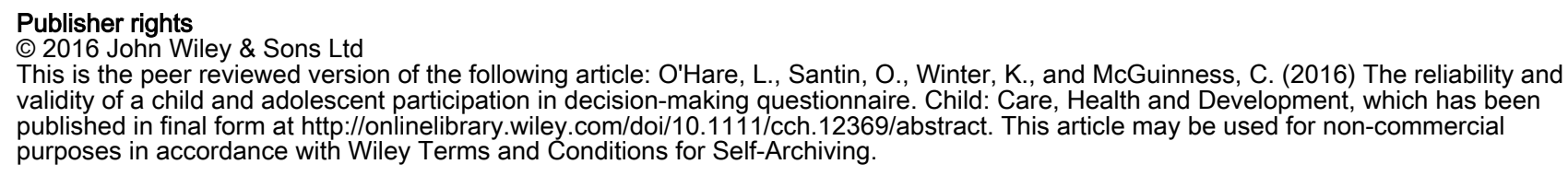

This is the peer reviewed version of the following article: O'Hare, L., Santin, O., Winter, K., and McGuinness, C. (2016) The reliability and validity of a child and adolescent participation in decision-making questionnaire. Child: Care, Health and Development, which has been published in final form at http://onlinelibrary.wiley.com/doi/10.1111/cch.12369/abstract. This article may be used for non-commercial purposes in accordance with Wiley Terms and Conditions for Self-Archiving.

\section{General rights}

Copyright for the publications made accessible via the Queen's University Belfast Research Portal is retained by the author(s) and / or other copyright owners and it is a condition of accessing these publications that users recognise and abide by the legal requirements associated with these rights.

\section{Take down policy}

The Research Portal is Queen's institutional repository that provides access to Queen's research output. Every effort has been made to ensure that content in the Research Portal does not infringe any person's rights, or applicable UK laws. If you discover content in the Research Portal that you believe breaches copyright or violates any law, please contact openaccess@qub.ac.uk. 


\section{Corresponding Author}

Dr Liam O'Hare, PhD, Senior Research Fellow, Centre for Effective Education, School of Education, Queen's University Belfast, 69-71 University Street, Belfast, BT7 1HL, +44 (0)28 90975973, l.ohare@qub.ac.uk

Dr Olinda Santin, School of Nursing and Midwifery, Queen's University Belfast, Medical Biology Centre, 97 Lisburn Road, Belfast, Northern Ireland, BT9 7BL, +44 (0)28 9097 2292,

o.santin@qub.ac.uk

Dr Karen Winter, School of Sociology, Social Policy and Social Work, Queen's University Belfast, 6 College Park, Belfast BT7 1LP, +44 (0)28 9097 3917, k.winter@qub.ac.uk

Professor Carol McGuinness, Centre for Effective Education, School of Education, Queen's University Belfast, 69-71 University Street, Belfast, BT7 1HL, +44 (0)28 9097 5913, c.mcguinness@qub.ac.uk

Key Words:

Children's Views; Looked-After children; Cognitive Ability; Measurement 


\section{Abstract \\ Background}

There is a growing impetus across the research, policy and practice communities for children and young people to participate in decisions that affect their lives. Furthermore, there is a dearth of general instruments that measure children and young people's views on their participation in decision making. This paper presents the reliability and validity of the Child and Adolescent Participation in Decision Making Questionnaire (CAP-DMQ) and specifically looks at a population of looked-after children where a lack of participation in decision making is an acute issue.

\section{Methods}

The participants were 151 looked after children and adolescents between 10-23 years of age who completed the 10 item CAP-DMQ. Of the participants 113 were in receipt of an advocacy service that had an aim of increasing participation in decision-making with the remaining participants not having received this service.

\section{Results}

The results showed that the CAP-DMQ had good reliability (Cronbach's alpha $=.94$ ) and showed promising uni-dimensional construct validity through an exploratory factor analysis. The items in the CAP-DMQ also demonstrated good content validity by overlapping with prominent models of child and adolescent participation (Lundy 2007) and decision making (Halpern 2014). A regression analysis showed that age and gender were not significant predictors of CAP-DMQ scores but receipt of advocacy was a significant predictor of scores (effect size $d=.88$ ), thus showing appropriate discriminant criterion validity.

\section{Conclusion}

Overall, the CAP-DMQ showed good reliability and validity. Therefore, the measure has excellent promise for theoretical investigation in the area of child and adolescent participation in decision making and equally shows empirical promise for use as a measure in evaluating services which have increasing the participation of children and adolescents in decision making as an intended outcome. 


\section{Introduction}

There is a wide range of decision making measures related to children and young people's issues. These measures fall into three interrelated categories namely: measures assessing children's decision making style and how they cope with their decisions (Children's Coping Strategies Checklist, Gaylord-Harden et al. 2008); measures for specific decisions children make such as career choices and health care decisions (The Severity and Acuity of Psychiatric Illness Scale - Lyons 1998); and measures for organisations, adults and parents on the extent to which they include children in decision making processes (Family Decision-Making Attitude Scale - Stanley 1978). Most of these existing measures do not directly assess children's general participation in decision making. Those that do are often context bound to a particular issue or completed by adults regarding their children's involvement in decision making. The authors of this paper know of no standardised measure that specifically looks at children's views on their general participation in decision making. To address this gap in participation measures, we have developed the Child and Adolescent Decision Making Participation Questionnaire (CAP-DMQ).

The development of such a measure is useful for a number of reasons. There is a wide range of work dedicated to supporting children's participation in decision making (Lansdown 1995) and linked scholarship emphasising its importance in a variety of contexts, for example, advocacy services (Dalrymple 2002; Boylan \& Dalrymple 2011), the courts (Berrick et al. 2015), health-care (Coyne 2008; Davies \& Randall 2015) and schools (Lansdown et al. 2014). We argue that a general measure of decision making participation would be useful in all these contexts for both theoretical and empirical investigation. A general measure could be used to monitor children's participation and ensure that it is overlapping with the aims and objectives of particular services. Furthermore, in a context where research regarding the relationship between increased participation and better outcomes is only now beginning to emerge (Vis et al. 2011; Davey 2010), a standardised measure could be used as a measure to link participation in decision making to real outcomes in children's lives such as health, education and other social factors. As the body of evidence grows around the benefits of children's participation in decision making, then it could be seen as a valuable outcome in itself and a measure such as the one proposed in this paper, the CAP-DMQ, could be used to evaluate the effects of services and processes directly on child and adolescent decision making participation. Finally, it is argued that reliable and valid measures of child and adolescent participation in decision making are necessary for the theoretical development of concepts and frameworks in a field of inquiry that intersects both theories of participation and decision making. 
Given the potential benefits of such a broad ranging general measure, it is important to consider the characteristics which would make it suitable. The importance of reliability and validity for a questionnaire is well established in the psychometric literature (Kline 2014). A reliable measure would ensure that there is consistency in response across different groups of children. In other words, children respond to all the items in the measure in a consistent pattern regardless of their gender, age, ability and social circumstances (Hogan 2013). A valid instrument would truly measure decision making participation, that is, reflect actual levels of participation, overlap with the theoretical content of models of decision making participation and would effectively detect differences between individuals who have different levels of participation in decision making. Usability and engagement is also an important characteristic of questionnaires, particularly for use with children and young people and those who work with them (Bell 2007). Issues that arise include: simple administration guidelines with a low requirement for technical expertise; short enough in length as not to induce fatigue in children; a short administration time in order to collect data from large numbers of participants; and suitable presentation to engage the children. Ultimately, these three main issues of reliability, validity and usability will be discussed in the following paper with regard to the CAP-DMQ. Firstly, the paper explores the literature on the two main issues: the development and importance of decision making; and child and adolescent participation.

\section{Models of decision making}

Decision-making is often described as choosing between alternatives. However, as Halpern (2014) outlined in her textbook chapter on decision-making, models of decision-making are more complex than that, and are generally considered to have a number of cognitive sub-tasks that require different types of critical thinking: (1) identifying when a decision needs to be made: (2) selecting and interpreting relevant information; (3) generating alternative courses of action, and predicting the consequences of each; (4) evaluating the consequences (pros and cons) and weighing them up; and (5) identifying the best course of action and following it through. While these decision-making steps indicate a highly 'rational' model, decisions are normally made in situations in the absence of complete information, often in emotional or stressful circumstances, thus making the evaluation of the risks and benefits of alternative courses of action very difficult.

More recent research (Albert \& Steinberg 2011) emphasises the social and emotional factors that can influence young people when faced with the typical risky decisions that are part of growing up (e.g., smoking, consuming alcohol, taking drugs, engaging in risky sexual behaviour and so on). Good decision making is now considered as interplay between cognitive and socio-emotional factors, 
pointing to the functional significance of decision-making in the development of young people, for self-regulation and self-management (e.g., Byrnes 2011).

For these reasons, it is important that young people become more aware of the processes of decision-making and some of the potential pitfalls (e.g., not considering enough options, overestimating the likelihood of positive outcomes, the effects of current mood on decision-making, as well as social factors such as peer pressure). Engaging children and young people in the decisionmaking that affects their lives enables them to take an active role, allowing them to practice the appropriate critical thinking and decision-making skills and to become more confident about using them in the future.

\section{Child and adolescent participation in decision making}

A growing body of research reflects the fact that participation in decision making, whether in education, health or social services, has beneficial developmental effects. Recent school related research (Lansdown et al. 2014) citing a range of work, has highlighted that participation in decision making can lead to developmental benefits in relation to self-esteem, cognitive abilities, social skills and respect for others. In a scoping review of research evidence regarding the effects of participation on health outcomes (Vis et al. 2011), it was found that children and young people's involvement in decision making, when it went well, had a four stranded positive 'therapeutic effect' in that it led to better child/professional relationships, higher levels of self-esteem in children and young people, increased their sense of mastery and control and reduced their stress and anxiety.

When involvement in decision making was less evident, the same research (Vis et al. 2011) found that effects on health outcomes were more likely to be negative, including feelings of helplessness and lower levels of confidence. In a related study (Coates \& Howe 2014) regarding youth participation in mental health settings, several benefits to individuals related to their involvement in decision making are noted, including: enhanced sense of belonging; feelings of being valued; and the development of social skills and self-esteem.

These beneficial developmental effects are also strongly evidenced in relation to advocacy services, the aims of which are threefold: to support children and young people in decision making fora; to resolve problems; and to empower them to engage in decision making fora (Oliver 2006; Hardwick 2013). Following engagement with an advocate, children and young people commonly report high levels of satisfaction in terms of sorting out specific problems and support (Oliver 2006; Elsley 2010; Brady 2011). 
What is missing from this body of knowledge regarding benefits is a generalised measure that provides a clear account of children and young people's level of engagement in decision-making. The development of such a measure would be helpful in seeking to further understand, in a more systematic way, experiences of involvement in decision making, the extent of involvement; and the effectiveness of, and outcomes associated with, that engagement in decision-making fora.

More broadly, and from a child rights' perspective, a participation measure would act as an indicator ensuring that the participation rights of children and young people (as 'rights bearers') are upheld and protected and that those on whom obligations are placed ('duty bearers') are held to account. A particular benefit of the CAP-DMQ measure outlined in this article (that is expanded upon subsequently) is that it can be mapped onto an existing model of children and young people's right to involvement in decision making (Lundy 2007) and which has four key elements:

SPACE: Children must be given safe, inclusive opportunities to form and express their view VOICE: Children must be facilitated to express their view

AUDIENCE: The view must be listened to

INFLUENCE: The view must be acted upon, as appropriate.

Lundy (2007, p. 933)

In addition, the CAP-DMQ captures some of the core thinking skills which are typical of normative models of decision-making such as that outlined by Halpern (2014) in the previous section, for example, identifying relevant information, evaluating pros and cons. Thus these two models of participation and decision making respectively will be returned to in the results section where items in the CAP-DMQ will be analysed for overlap with the two models. Effectively, this acts as an analysis of content validity of the CAP-DMQ as a measure of child and adolescent decision making participation.

In summary, this paper aims to provide a reliable, valid and usable questionnaire that can be utilised for both theoretical development and service evaluation purposes in the area of child and adolescent participation in decision making, with the aim of protecting and upholding child and adolescent participation rights, helping to understand their decision making processes and ultimately improving their outcomes. 


\section{Methodology}

\section{Questionnaire Development \& Administration}

A group of cognitive psychologists and advocacy practitioners developed a pool of 10 items designed to produce a General Questionnaire for Child and Adolescent Decision Making Participation. The questionnaire items were presented as Likert scale items. A lower score on the scale denoted a higher level of decision-making participation. For example, agree strongly = 1 and disagree strongly was $=6$, see the following example:

1. I feel involved in making decisions in my life.

1

Agree Strongly

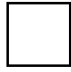

2

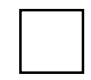

3

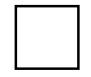

4

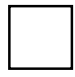

5

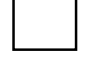

6

Disagree Strongly

Prior to data collection for the main study the questions were piloted with five young people. The pilot aimed to identify any potential difficulties in relation to understanding and usability (the pilot included two young people with learning difficulties). The participants in the pilot study raised no concerns and felt the questionnaire was suitable for varying levels of abilities.

\section{Participant Sample}

The study participants were recruited through an advocacy organisation for Looked after Children and the organisation facilitated the conduct of the study by identifying care experienced young people. Young people were invited to participate through a number of approaches including a mail shot, advertising at young people conferences and group attendance. Eligible young people were forwarded a questionnaire pack including the CAP-DMQ and a short demographic questionnaire. Those who did not return their survey were sent a reminder after two weeks.

In total, 151 care experienced young people participated in this study. The participants were aged 10-23, 52 of which were male and 81 female (eighteen participants did not provide gender information). Of those young people who responded, 113 had received advocacy, 38 had not and there were three missing responses. The reason for including young people who had not yet received the advocacy service was to provide data to assess the potential of the questionnaire as an outcome evaluation tool to distinguish between different groups, that is, to assess its discriminant validity. 
The participants provided informed consent to complete the questionnaire and were free to withdraw their consent and/or data at any time. Furthermore, children and young people were not asked to complete the questionnaire if participation was deemed detrimental to their care by the advocacy organisation staff. Ethical review was provided through the relevant ethics committee.

\section{Study Design \& Analysis}

This study is a psychometric investigation of the reliability and validity of the CAP-DMQ. It is composed of two main analytical components namely: internal construct reliability and validity (including a reliability analysis, exploratory factor analysis and content validity analysis); and external criterion validity exploring the scale's ability to discriminate between different groups (i.e., an advocacy and non-advocacy group of children and adolescents). 


\section{Results}

\section{Reliability Analysis}

The first analysis conducted on the CAP-DMQ data was a reliability analysis checking internal consistency of participant responses to the instrument. The Cronbach's alpha for the 10 item scale was .94 showing high internal consistency and the analysis also showed that removing any of the 10 items would reduce the reliability of the scale.

\section{Construct Validity \& Content Validity}

Construct validity explores if the scale measures what it purports to measure, i.e., child and adolescent participation in decision making. Relatedly, content validity examines overlap of the items being measured with concepts, models or frameworks of the topic under investigation.

In terms of construct validity the authors carried out an exploratory factor analysis. The first step was to investigate how many factors were being measured by the instrument and if one or more different factors are being measured by the data. To do this we examined a scree plot for the CAP$\mathrm{DMQ}$ and from this it was very clear that only one factor was being measured by the 10 items. Having obtained evidence from the scree plot that it was uni-dimensional, the next stage was to conduct a factor analysis on the items. This was conducted using a principal components analysis and the results of this step are presented in Table 1 below. This table also presents the items in the CAP-DMQ ordered in terms of their factor loadings from highest to lowest. Factor loadings represent the strength of the relationship between an individual item and the overall factor or total scale score. Ideally, in a principal component analysis, factor loadings should be above 0.4 to warrant their inclusion in the final scale. In this case all the items had a strong relationship with the overarching factor with the lowest factor loading being 0.74 .

Table 1 also includes a content validity analysis of the CAP-DMQ. As stated earlier, this analysis explores whether there is an overlap between the CAP-DMQ items and prevalent models of child and adolescent participation in decision making. In this case the authors have chosen to analyse the items using the four elements in the child participation model outlined above that is: Space; Voice; Audience; and Influence (Lundy 2007). In addition, the items were also analysed for their overlap with Halpern's (2014) previously described framework of decision making.

\section{Insert Table 1 here}


Looking at the items in the questionnaire it can said that each of them is covered by elements in the Lundy (2007) model. Furthermore, it can be seen that components of Halpern's (2014) framework overlap with7/10 items in the measure.

\section{External Criterion Related Validity}

Having examined the internal measurement nature of the instrument through reliability, construct and content validity, it is also important to explore how the measure performs against external criteria specifically: is the instrument able to discriminate between groups of children and young people who have experienced different levels of decision-making participation support? This is examined using the questionnaires total score (rather than individual item scores). Therefore, it is important to look at the distribution of the total scores to check for skewness (a proxy for floor and ceiling measurement effects). The overall mean scale score in the participant population was 3.69, which puts the mean score slightly above the mid-point (i.e., 3.5); on referring back to the Likert scale this indicates very slightly more disagreement with the statements than agreement over the whole population. Next, the skewness the statistic for the sample was -.11 (SE $=.20)$, which indicates slight skew towards higher values, i.e., some individuals with less agreement. However, it can be stated that the overall pattern of responses is normally distributed. Returning to the issue of discriminant validity, the regression model reported in Table 2 shows that neither age nor gender were predictors of CAP-DMQ scores, indicating that the instrument is suitable for use with male and female adolescents in the age group investigated. In contrast, having experienced advocacy was a significant predictor of CAP-DMQ scores. Again, this is a promising result as the advocacy service aims to increase the decision-making participation of its clients. Overall, the predictors in the model account for $13 \%$ of the variance (adjusted $r^{2}=.129, \mathrm{SE}=1.33$ ) in CAP-DMQ.

\section{Insert Table 2 here}

Although the current study is not an evaluation of the advocacy service, it is potentially interesting to look at the effect size of the influence of the service on decision making participation as measured by the CAP-DMQ. The young people in the advocacy service reported significantly better participation in decision-making scores compared to those who had not experienced any advocacy involvement. However, this effect cannot be attributed with confidence to the advocacy service without the use of a more robust research design including a control group such as a randomised controlled trial. 


\section{Insert Table 3 here}

\section{Conclusion}

Overall, the CAP-DMQ showed good reliability and validity through the various statistical tests. Internal factors such as reliability and construct validity showed evidence of the measures robustness. Also, the CAP-DMQ demonstrated good external validity through several tests: its total score displayed normal distribution; it did not discriminate between male and female young people across a range of ages; and showed clear discrimination between the scores of advocacy and nonadvocacy groups. Thus the results also provided some indication that the CAP-DMQ could work well as an outcome measure in evaluations of advocacy services for looked after children and potentially other services which hold similar aims.

The analysis of content validity in Table 1 is one further form of validity worth considering for the CAP-DMQ. The main purpose of that analysis was to investigate if the items overlapped with the two models of participation and decision making proposed by Lundy (2007) and Halpern (2014) respectively. There are a very many interesting debates which could arise about the placement, overlap and gaps linking the items with these models. Unfortunately, there is not room in this paper to discuss each of these in turn. However, by way of example one interesting observation is the overlap with both voice and space on two of the items (number 5 and 6). This may reflect the unique type of participation required around decision making by children and adolescents. Here we can see the value of exploring content validity with both a participation model and a model of decision making. It is arguable that it is 'Voice' (Children must be facilitated to express their view) requires a particular type of facilitation to help children express their view in the often cognitively and emotionally challenging task of making important life decisions. Perhaps voice in these two items is represented by facilitation of two different decision making skills, that is: Predicting consequences and weighing alternatives (in number 5); and Selecting and interpreting information (in number 6 ). Regardless of the precise accuracy of this particular example, it indicates that further theoretical and empirical investigation concerning the interactions between child and adolescent participation and decision making is a fruitful area of future research.

There are some limitations with this study, and several linked suggestions for future research. First, the construct validity work in the study conducted was exploratory factor analysis (EFA) rather than confirmatory factor analysis (CFA). The researchers chose this option as this study was exploring the 
construct validity properties of the CAP-DMQ and encourage other researchers to test this measure and its apparent uni-dimensional factor structure with a CFA in similar or other populations. Second, although the measure discriminated between advocacy and non-advocacy groups it is uncertain whether the experience of advocacy truly caused increased decision-making participation. More robust evaluation designs such as a Randomised Controlled Trial would be required to test this. However, the CAP-DMQ may have potential to be used in such a study due to the lack of similar available measures. Furthermore, the CAP-DMQ could have potential to assess decision making participation in other contexts, such as disability services, health care and educational settings. In addition, the CAP-DMQ exhibits the characteristics of a usable measure for these purposes because it is short in length and administration time and also does not require extensive technical expertise to administer or analyse the resulting data.

\section{Key Messages}

- There is a lack of general measures of child and adolescent participation in decision making

- The CAP-DMQ is short usable tool for investigating child and adolescent participation in decision making

- This paper provides evidence of the reliability and validity of the CAP-DMQ

- The CAP-DMQ can be used for developing models and evaluating practice in advocacy service provision 


\section{References}

Albert, D., \& Steinber, L. (2011) Judgement and decision making in adolescence. Journal of Research on Adolescence, 21(1), 211-224.

Bell, A. (2007) Designing and testing questionnaires for children. Journal of Research in Nursing, 12(5), 461-469.

Berrick, J. D., Dickens, J., Pösö, T. \& Skivenes, M. (2015) Children's involvement in care order decision-making: a cross-country analysis. Child Abuse and Neglect,

Boylan, J. \& Dalrymple, J. (2011) Advocacy, social justice and children's rights. Practice, 23(1), 19-30.

Brady, L. (2011) Where is my Advocate? A Scoping Report on Advocacy Services for Children and Young people in England. Office of the Children's Commissioner, London.

Byrnes, James, P. (2011) The nature and development of decision making: A self-regulatory model. New York: Routledge.

Coates, D. \& Howe, D. (2014) The importance and benefits of youth participation in mental health settings from the perspective of the headspace Gosford Youth Alliance in Australia. Children and Youth Services Review, 46, 294-299.

Coyne, I. (2008) Children's participation in consultations and decision-making at health service level: a review of the literature. International Journal of Nursing Studies, 45(11), 1682-1689.

Dalrymple, J. (2002) Family Group Conferences and youth advocacy: the participation of children and young people in family decision making. European Journal of Social Work, 5(3), 287-299.

Davey, C., Lea, J., Shaw, C. \& Burke, T. (2010) Children's Participation in Decision-Making. Children's Rights Alliance England and National Children's Bureau, London.

Davies, A. \& Randall, D. (2015) Perceptions of children's participation in their healthcare: a critical review. Issues in Comprehensive Pediatric Nursing, 38(3), 202-221. 
Elsley, S. (2010) 'Advocacy Makes You Feel Brave': Advocacy Support for Children and Young People in Scotland. The Scottish Executive, Edinburgh, Scotland.

Gaylord-Harden, N. K., Gipson, P., Mance, G. \& Grant, K. E. (2008) Coping patterns of African American adolescents: a confirmatory factor analysis and cluster analysis of the Children's Coping Strategies Checklist. Psychological Assessment, 20(1), 10.

Halpern, D.F. (2014). Thought and knowledge: An introduction to critical thinking ( $5^{\text {th }}$ edition). New York: Psychology Press. (Chapter 5 on decision-making)

Hardwick, L. (2013) Advocacy versus social work: what the setting-up of an advocacy rights hub reveals about social work's ability to promote social inclusion, British Journal Social Work, doi:10.1093/bjsw/bct072

Hogan, T. P. (2013) Psychological Testing: A Practical Introduction. Wiley Global Education, Hoboken, New Jersey, USA.

Kline, P. (2014). The new psychometrics: Science, psychology and measurement. Routledge.

Lansdown, G. (1995) Taking Part: Children's Participation in Decision Making. Institute for Public Policy Research, London.

Lansdown, G., Jimerson, S. R. \& Shahroozi, R. (2014) Children's rights and school psychology: children's right to participation. Journal of School Psychology, 52(1), 3-12.

Lundy, L. (2007) 'Voice' is not enough: conceptualising Article 12 of the United Nations Convention on the rights of the child. British Educational Research Journal, 33(6), 927-942.

Lyons, J. S. (1998) The Severity and Acuity of Psychiatric Illness Scales: An Outcomes-Management and Decision-support System: Child and Adolescent Version: Manual. Psychological Corporation

Oliver, C., Knight, A. \& Candappa, M. (2006) Advocacy for Looked After Children and Children in Need: Achievements and Challenges. Institute of Education, University of London: London. 
Participation in Decision Making Questionnaire

Stanley, S. F. (1978) Family education to enhance the moral atmosphere of the family and the moral development of adolescents. Journal of Counseling Psychology, 25(2), 110.

Vis, S. A., Strandbu, A., Holtan, A., \& Thomas, N. (2011). Participation and health-a research review of child participation in planning and decision-making. Child \& Family Social Work, 16(3), 325-335. 
Table 1 Shows the items in the CAP-DMQ questionnaire along with their factor loadings from the principal components analysis and also includes a content validity analysis based on Lundy (2007) model of child participation and Halpern (2014) model of decision making.

\begin{tabular}{|c|c|c|c|c|}
\hline & CAP-DMQ Items & $\begin{array}{l}\text { Factor } \\
\text { Loading }\end{array}$ & $\begin{array}{c}\text { Content } \\
\text { Validity } \\
\text { Participation } \\
\text { (Lundy 2007) }\end{array}$ & $\begin{array}{l}\text { Content Validity } \\
\text { Decision-Making } \\
\text { (Halpern 2014) }\end{array}$ \\
\hline 1 & $\begin{array}{l}\text { Information to make a decision is } \\
\text { presented to me in a way I understand }\end{array}$ & .890 & Voice & $\begin{array}{l}\text { Interpreting } \\
\text { information }\end{array}$ \\
\hline 2 & $\begin{array}{l}\text { I am given the full information to } \\
\text { make a decision }\end{array}$ & .867 & Voice & $\begin{array}{l}\text { Interpreting } \\
\text { information }\end{array}$ \\
\hline 3 & $\begin{array}{l}\text { I feel involved in making decisions in } \\
\text { my life }\end{array}$ & .859 & Space & \\
\hline 4 & $\begin{array}{l}\text { I am given the opportunity to weigh } \\
\text { up the pros and cons to make a } \\
\text { decision }\end{array}$ & .854 & Space & $\begin{array}{c}\text { Predicting } \\
\text { consequences and } \\
\text { weighing alternatives }\end{array}$ \\
\hline 5 & $\begin{array}{l}\text { I have the ability to weigh up the pros } \\
\text { and cons to make a decision }\end{array}$ & .828 & $\begin{array}{l}\text { Voice \& } \\
\text { space }\end{array}$ & $\begin{array}{c}\text { Predicting } \\
\text { consequences and } \\
\text { weighing alternatives } \\
\end{array}$ \\
\hline 6 & $\begin{array}{l}\text { I can gather the right information to } \\
\text { make a decision }\end{array}$ & .806 & $\begin{array}{l}\text { Voice \& } \\
\text { space }\end{array}$ & $\begin{array}{l}\text { Selecting and } \\
\text { interpreting } \\
\text { information } \\
\end{array}$ \\
\hline 7 & $\begin{array}{l}\text { Others ask my opinions when making } \\
\text { decisions. }\end{array}$ & .801 & Audience & \\
\hline 8 & $\begin{array}{l}\text { Young people should be involved in } \\
\text { the decision making process }\end{array}$ & .768 & Audience & \\
\hline 9 & $\begin{array}{l}\text { When I make a decision this is } \\
\text { followed through by action that I } \\
\text { want. }\end{array}$ & .751 & Influence & $\begin{array}{l}\text { Following through a } \\
\text { decision }\end{array}$ \\
\hline 10 & I make decisions on big things. & .743 & Influence & Defining importance \\
\hline
\end{tabular}


Table 2 Regression co-efficient of age, gender and advocacy group for predicting GQ-GQ-CADMaP scores

\begin{tabular}{|c|c|c|c|c|c|}
\hline \multirow{2}{*}{$\begin{array}{l}\text { Dependent Variable: } \\
\text { Total GQ-CADMaP } \\
\text { score }\end{array}$} & \multicolumn{2}{|c|}{$\begin{array}{l}\text { Unstandardized } \\
\text { Coefficients }\end{array}$} & \multirow{2}{*}{$\begin{array}{c}\begin{array}{c}\text { Standardized } \\
\text { Coefficients }\end{array} \\
\text { Beta } \\
\end{array}$} & \multirow[t]{2}{*}{$\mathrm{t}$} & \multirow[t]{2}{*}{ Sig. } \\
\hline & $\mathrm{B}$ & Std. Error & & & \\
\hline (Constant) & 6.271 & .888 & & 7.060 & .0001 \\
\hline Age & -.075 & .049 & -.125 & -1.509 & .134 \\
\hline $\begin{array}{l}\text { Gender ( } \text { male = 1, } \\
\text { female }=0 \text { ) }\end{array}$ & -.358 & .241 & -.123 & -1.490 & .139 \\
\hline $\begin{array}{l}\text { Group (advocacy =1, } \\
\text { Non-Advocacy }=0 \text { ) }\end{array}$ & -1.174 & 282 & -.344 & -4.169 & .0001 \\
\hline
\end{tabular}


Table 3 Effect size of difference in participation in decision-making between advocacy and nonadvocacy groups

\begin{tabular}{|c|c|c|c|c|c|}
\hline \multirow[t]{2}{*}{ Outcome Measures } & \multicolumn{2}{|c|}{ Mean Scores (with SDs) ${ }^{1}$} & \multirow{2}{*}{$\begin{array}{l}\text { Effect }^{2} \\
\text { Size (d) }\end{array}$} & \multirow{2}{*}{$\begin{array}{c}95 \% \\
\text { Confidence } \\
\text { Interval }\end{array}$} & \multirow{2}{*}{$\begin{array}{c}\text { Significance } \\
\text { of } \\
\text { Difference* }\end{array}$} \\
\hline & $\begin{array}{l}\text { Non- } \\
\text { advocacy } \\
\text { Group }\end{array}$ & $\begin{array}{c}\text { Advocacy } \\
\text { Group }\end{array}$ & & & \\
\hline Decision Making & $\begin{array}{c}4.53 \\
(0.88)\end{array}$ & $\begin{array}{c}3.35 \\
(1.47)\end{array}$ & -0.88 & $\begin{array}{c}{[-0.50,-} \\
1.26]\end{array}$ & $<.001$ \\
\hline
\end{tabular}

\footnotetext{
${ }^{1}$ A lower score on the scale denoted a higher level of decision making participation, as strongly agree was $=1$ and strongly disagree was $=6$. As a result, negative signs denote the positive changes in the intervention group in relation to their decision making participation.

${ }^{2}$ The specific effect size measure used here is the standardised mean difference calculated as the difference in these two mean scores divided by the pooled standard deviation for the test scores for both groups (i.e. ,Cohen's d.
} 